\title{
GMR
}

\section{Association between interleukin 17A gene polymorphisms and risk of coronary artery disease}

\author{
X.S. Zheng ${ }^{1}$, S. Wang ${ }^{2}$ and $\mathrm{M} . \mathrm{Ni}^{3}$ \\ ${ }^{1}$ Intensive Care Unit, Nanyang City Center Hospital, Nanyang, China \\ 2Department of Gastroenterology, Nanyang City Center Hospital, Nanyang, China \\ ${ }^{3}$ Department of Endocrinology, Nanyang City Center Hospital, Nanyang, China \\ Corresponding author: X.S. Zheng \\ E-mail: zhengxs_xs@163.com \\ Genet. Mol. Res. 15 (1): gmr.15017074 \\ Received October 24, 2015 \\ Accepted December 5, 2015 \\ Published February 5, 2016 \\ DOI http://dx.doi.org/10.4238/gmr.15017074
}

ABSTRACT. Coronary artery disease (CAD) represents a leading cause of morbidity and mortality worldwide, and genetic factors contribute to the development of this disease. We conducted a case-control study to assess the association between interleukin 17A (IL17A) rs2275913 and rs3748067 polymorphisms and development of CAD. A total of 372 CAD patients and 372 healthy controls were recruited in our investigation between January 2013 and December 2014. Genotyping of IL17A rs2275913 and rs3748067 was carried out using polymerase chain reaction combined with restriction fragment length polymorphism. Logistic regression analysis revealed that $\mathrm{CC}$ [odds ratio $(\mathrm{OR})=3.81,95 \%$ confidence interval $(\mathrm{Cl})=2.11-7.16$ ] and $\mathrm{TC}+\mathrm{CC}(\mathrm{OR}=1.54,95 \% \mathrm{Cl}=1.11-2.14)$ rs3748067 genotypes were associated with an increased risk of CAD compared to the TT variant. Individuals carrying the $\mathrm{TC}+\mathrm{CC}$ genotype were more likely to have a higher risk of CAD if they were smokers, with an adjusted OR (and $95 \% \mathrm{Cl}$ ) of 2.20 (1.31-3.71). In conclusion, we suggest that the CC and TC+CC genotypes 
of rs3748067 are connected with increased risk of CAD in comparison to the wide-type genotype, particularly in smokers.

Key words: Interleukin 17; Polymorphism; Coronary artery disease

\section{INTRODUCTION}

Coronary artery disease (CAD) represents a leading cause of death worldwide, and more than $80 \%$ of cases occur in low-to-middle income countries (Greenland et al., 2010). It is well known that the development of CAD is a complex, multistep, and multifactorial process, involving various environmental factors. Previous studies have reported that the male gender, hypertension, tobacco use, alcohol consumption, and diabetes mellitus as well as high serum cholesterol contribute to the development of CAD (Greenland et al., 2010). However, not all individuals exposed to similar risk factors of CAD influences go on to develop this disease, suggesting that hereditary factors also contribute to the susceptibility to this condition.

Previous study has reported that the inflammation plays an important role in the risk of atherosclerosis (Weber and Hristov, 2015). The comparatively new interleukin 17 (IL17) cytokine family consists of six members (IL17A to F), which has been implicated in many chronic inflammatory diseases, such as ulcerative colitis risk, asthma and tuberculosis (Li et al., 2014; Bulat-Kardum et al., 2015; Narbutt et al., 2015; Isailovic et al., 2015). The human IL17A gene, located in 6q12, is the most important member of the IL17 group. Previous studies have tested the association between IL17 gene polymorphisms and risk of cardiovascular disease (Pei et al., 2009; Zhang et al., 2011; Vargas-Alarcón et al., 2015), but with inconclusive results. Therefore, we performed a case-control study to evaluate the association between two common IL17A SNPs, rs2275913 and rs3748067, and development of CAD.

\section{MATERIAL AND METHODS}

\section{Subjects}

A total of 372 CAD patients were consecutively collected from Nanyang City Center Hospital between January 2013 and December 2014. Individuals were diagnosed using angiography, with CAD being defined as a stenosis diameter of $50 \%$ in any of the main coronary arteries. Patients with congenital heart disease, autoimmune-related disease, malignant tumor, or serious renal or liver diseases were excluded from this study.

In total, 372 health control subjects attending regular health checkups at our hospital over the same period were also recruited. Individuals were confirmed as having no history of CAD, autoimmune-related disease, or renal disease. Each control subject was matched to each case by gender and age.

Demographic and lifestyle data of CAD patients and control subjects were collected using a structured questionnaire, and included details regarding age, gender, body mass index, hypertension, alcohol consumption, and tobacco smoking. Clinical data collected from medical records consisted of total cholesterol (TC), low- and high-density lipoprotein cholesterol (LDL-C and HDL-C, respectively), and triglyceride (TG) measurements.

A signed informed consent form was obtained from each subject before participation. The 
collection of blood samples for this study was approved in advance by the Ethics Committee of Nanyang City Center Hospital.

\section{Genetic analysis}

Each participant was asked to provide a 5-mL peripheral venous blood sample after enrolling in our study, from which DNA was then isolated by salt extraction. Genotyping of IL17A rs2275913 and rs3748067 was performed by polymerase chain reaction (PCR) combined with restriction fragment length polymorphism. The primers for IL17A rs2275913 and rs3748067 were designed using the MassARRAY Assay Design 3.1 software (Sequenom, San Diego, CA, USA). The resulting PCR fragments were subsequently digested with restriction enzymes specific to the sequence of interest, namely BstENI for rs3748067 and Avall for rs2275913. Amplification conditions were as follows: an initial DNA denaturation step at $94^{\circ} \mathrm{C}$ for $5 \mathrm{~min}$, then $30 \mathrm{cycles}$ of denaturation at $94^{\circ} \mathrm{C}$ for $1 \mathrm{~min}$, annealing at $55^{\circ} \mathrm{C}$ for $1 \mathrm{~min}$, and extension at $72^{\circ} \mathrm{C}$ for $2 \mathrm{~min}$, followed by a final extension step at $72^{\circ} \mathrm{C}$ for $5 \mathrm{~min}$.

\section{Statistical analysis}

Differences in demographic and clinical characteristics between CAD patient and control groups were compared using the Pearson chi-square test or the Student $t$-test. Genotype distributions in the control group were tested for deviation from Hardy-Weinberg equilibrium. Pearson chi-square test was used to examine differences in genotypic distribution between CAD patients and controls. Odds ratios (ORs) and their $95 \%$ confidence intervals (Cls) were estimated using multiple-logistic regression models adjusted for confounding factors. Statistical analyses were performed using the SPSS 16.0 statistical software (SPSS Inc., Chicago, IL, USA), and all tests were two-sided, with $\mathrm{P}$ values $<0.05$ indicating statistical significance.

\section{RESULTS}

The demographic and clinical data of CAD patients and control subjects are presented in Table 1. The chi-square test revealed that individuals with $C A D$ were more likely to have a higher $B M I$, suffer from hypertension, smoke tobacco, and drink alcohol $(P<0.05)$. Moreover, $C A D$ patients demonstrated higher TC, LDL-C, and TG levels, and lower HDL-C when compared with control subjects $(P<0.05)$.

In the control group, the distribution of rs2275913 genotypes was consistent with HardyWeinberg equilibrium ( $P=0.40)$, but that of rs 3748067 was not $(P=0.002)$. Using the chi-square test, a significant difference in the frequencies of rs 3748067 genotypes was established between the CAD and control groups (chi-square $=23.96, \mathrm{P}<0.001$ ). Logistic regression analysis showed that the CC and TC+CC rs3748067 genotypes, with adjusted ORs (and 95\%Cls) of 3.81 (2.11-7.16) and 1.54 (1.11-2.14), respectively, were associated with an increased risk of CAD when compared with the TT genotype (Table 2). However, no significant relationship between rs2275913 and CAD was found.

We also conducted gene-environment interaction analysis to investigate the influence of rs3748067, in combination with clinical and demographic characteristics, on CAD risk. We found that individuals carrying the TC+CC genotype were more likely to have CAD if they were smokers (adjusted $\mathrm{OR}=2.20,95 \% \mathrm{Cl}=1.31-3.71$; Table 3). However, no significant interaction between this polymorphism and BMI, hypertension, diabetes mellitus, or alcohol consumption was seen to effect CAD risk $(P>0.05)$. 
Table 1. Characteristics of coronary artery disease patients and control subjects.

\begin{tabular}{|c|c|c|c|c|c|c|}
\hline & CAD cases & \multirow[t]{2}{*}{$\%$} & Controls & \multirow[t]{2}{*}{$\%$} & \multirow{2}{*}{$\begin{array}{c}\text { Chi-square or } \\
t \text { - test }\end{array}$} & \multirow[t]{2}{*}{$P$ value } \\
\hline & $(N=372)$ & & $(N=372)$ & & & \\
\hline Mean age (years) & $62.15 \pm 11.30$ & & $61.74 \pm 10.95$ & & 0.50 & 0.31 \\
\hline$<60$ & 166 & 44.62 & 172 & 46.24 & & \\
\hline$\geq 60$ & 206 & 55.38 & 200 & 53.76 & 0.20 & 0.66 \\
\hline \multicolumn{7}{|l|}{ Gender } \\
\hline Male & 280 & 75.27 & 280 & 75.27 & & \\
\hline Female & 92 & 24.73 & 92 & 24.73 & 0.00 & 1.00 \\
\hline \multicolumn{7}{|l|}{$\mathrm{BMI}\left(\mathrm{kg} / \mathrm{m}^{2}\right)$} \\
\hline$<24$ & 244 & 65.59 & 276 & 74.19 & & \\
\hline$\geq 24$ & 128 & 34.41 & 96 & 25.81 & 6.54 & 0.01 \\
\hline \multicolumn{7}{|l|}{ Hypertension } \\
\hline No & 262 & 70.43 & 307 & 82.53 & & \\
\hline Yes & 110 & 29.57 & 65 & 17.47 & 15.13 & $<0.001$ \\
\hline \multicolumn{7}{|c|}{ Alcohol consumption } \\
\hline Non-drinkers & 173 & 46.51 & 213 & 57.26 & & \\
\hline Drinkers & 199 & 53.49 & 159 & 42.74 & 8.61 & 0.003 \\
\hline \multicolumn{7}{|l|}{ Tobacco smoking } \\
\hline Non-smokers & 196 & 52.69 & 235 & 63.17 & & \\
\hline Smokers & 176 & 47.31 & 137 & 36.83 & 8.39 & 0.004 \\
\hline $\mathrm{TC}(\mathrm{mmol} / \mathrm{dL})$ & $197.30 \pm 51.08$ & & $172.40 \pm 30.52$ & & 7.45 & $<0.001$ \\
\hline LDL-C (mmol/dL) & $112.65 \pm 27.42$ & & $98.30 \pm 26.45$ & & 6.71 & $<0.001$ \\
\hline $\mathrm{HDL}-\mathrm{C}(\mathrm{mmol} / \mathrm{dL})$ & $36.60 \pm 8.24$ & & $42.65 \pm 7.60$ & & 9.61 & $<0.001$ \\
\hline TGs (mmol/dL) & $135.35 \pm 42.10$ & & $114.30 \pm 28.55$ & & 7.37 & $<0.001$ \\
\hline
\end{tabular}

$\mathrm{CAD}=$ coronary artery disease; $\mathrm{BMI}=$ body mass index; $\mathrm{TC}=$ total cholesterol; $\mathrm{LDL}-\mathrm{C}=$ low-density lipoprotein cholesterol; HDL-C = high-density lipoprotein cholesterol; TG = triglycerides.

Table 2. IL17A rs2275913 and rs3748067 genotype distributions and their association with coronary artery disease risk.

\begin{tabular}{l|c|c|c|c|c|c|c|c}
\hline SNP & Base change & Patients & $\%$ & Controls & $\%$ & $P$ value for HWE & OR (95\%Cl) $)^{1}$ & $P$ value \\
\hline rs2275913 & & & & & & & & \\
\hline GG & & 162 & 43.55 & 179 & 48.12 & & 1.0 (Ref.) & - \\
\hline GA & & 170 & 45.7 & 163 & 43.82 & & $1.15(0.84-1.58)$ & 0.36 \\
\hline AA & G>A & 40 & 10.75 & 30 & 8.06 & 0.4 & $1.47(0.85-2.57)$ & 0.14 \\
\hline GA+AA & & 210 & 56.45 & 193 & 51.88 & & $1.20(0.89-1.62)$ & 0.21 \\
\hline rs3748067 & & & & & & & & \\
\hline TT & & 243 & 65.32 & 276 & 74.19 & & $1.0($ Ref.) & - \\
\hline TC & & 73 & 19.62 & 79 & 21.24 & & $1.05(0.72-1.53)$ & 0.79 \\
\hline CC & C>T & 57 & 15.32 & 17 & 4.57 & 0.002 & $3.81(2.11-7.16)$ & $<0.001$ \\
\hline TC+CC & & 130 & 34.95 & 96 & 25.81 & & $1.54(1.11-2.14)$ & 0.007 \\
\hline
\end{tabular}

${ }^{1}$ Adjusted for gender, age, body mass index, hypertension, diabetes mellitus, alcohol consumption, tobacco smoking, total cholesterol, low- and high-density lipoprotein cholesterol, and triglyceride measurements. SNP = single nucleotide polymorphism; HWE = Hardy-Weinberg equilibrium; OR = odds ratio; $\mathrm{Cl}=$ confidence interval; Ref. = reference. 
Table 3. Interaction between the rs 3748067 polymorphism and demographic and clinical characteristics in risk of coronary artery disease.

\begin{tabular}{|c|c|c|c|c|c|c|}
\hline \multirow{3}{*}{ Variable } & \multicolumn{4}{|c|}{ rs 3748067} & \multirow{3}{*}{ OR $(95 \% \mathrm{Cl})$} & \multirow{3}{*}{$P$ value } \\
\hline & \multicolumn{2}{|c|}{ TT } & \multicolumn{2}{|c|}{$\mathrm{TC}+\mathrm{CC}$} & & \\
\hline & Cases & Controls & Cases & Controls & & \\
\hline \multicolumn{7}{|l|}{ BMI $\left(\mathrm{kg} / \mathrm{m}^{2}\right)$} \\
\hline$<24$ & 163 & 204 & 81 & 72 & $1.41(0.95-2.09)$ & 0.08 \\
\hline$\geq 24$ & 80 & 72 & 48 & 24 & $1.80(0.97-3.39)$ & 0.06 \\
\hline \multicolumn{7}{|l|}{ Hypertension } \\
\hline No & 174 & 226 & 88 & 81 & $1.41(0.87-2.06)$ & 0.06 \\
\hline Yes & 69 & 50 & 41 & 15 & $1.98(0.95-4.28)$ & 0.06 \\
\hline \multicolumn{7}{|c|}{ Diabetes mellitus } \\
\hline No & 175 & 235 & 90 & 85 & $1.42(0.98-2.06)$ & 0.05 \\
\hline Yes & 68 & 41 & 39 & 11 & $2.14(0.94-5.13)$ & 0.05 \\
\hline \multicolumn{7}{|c|}{ Alcohol consumption } \\
\hline Non-drinkers & 112 & 157 & 61 & 56 & $1.53(0.96-2.42)$ & 0.06 \\
\hline Drinkers & 131 & 119 & 68 & 40 & $1.54(0.95-2.53)$ & 0.07 \\
\hline \multicolumn{7}{|c|}{ Tobacco smoking } \\
\hline Non-smokers & 141 & 173 & 55 & 62 & $1.09(0.69-1.70)$ & 0.7 \\
\hline Smokers & 102 & 103 & 74 & 34 & $2.20(1.31-3.71)$ & 0.002 \\
\hline
\end{tabular}

$\mathrm{OR}=$ odds ratio $\mathrm{Cl}=$ confidence interval; $\mathrm{BMI}=$ body mass index

\section{DISCUSSION}

Genetic susceptibility to cardiovascular disease has gained an increasing amount of attention as a research theme, leading to investigations of polymorphisms involved in the development of CAD. Inflammation and related cytokines are involved in both innate and acquired immune responses, and play a critical role in the inflammatory response, which contributes to the susceptibility to cardiovascular disease.

Recently, many studies have assessed the association between IL17A and susceptibility to many cardiovascular diseases (Zeng et al., 2013; Erbel et al., 2014; Lifanov et al., 2014; VargasAlarcón et al., 2015; Mormile, 2015; Wang et al., 2015). Based on an experimental investigation, Vargas-Alarcón et al. (2015) reported that the IL17A gene is involved in inflammatory immune responses and neuronal damage, including premature coronary diseases. In addition, Lifanov et al. (2014) reported an association between the 197A allele of the IL17A gene and low myocardial growth in athletes, suggesting that they have a pathogenetic function in this disease. Erbel et al. (2014) reported that functional blockade of IL17A prevents atherosclerotic lesion.

Three previous studies have assessed the association between IL17 gene polymorphisms and cardiovascular diseases. Pei et al. (2009) conducted a case-control examination of a Chinese population, the results of which indicated that the IL17F rs763780 polymorphism is unlikely to contribute to the development of myocardial infarction. In another case-control study of a Chinese population, Zhang et al. (2011) reported that IL17A rs8193037 is associated with increased risk of CAD and contributes to elevated IL17A expression in acute myocardial infarction. Vargas-Alarcón et al. (2015) conducted a case-control study with 900 premature CAD patients and 667 health controls, concluding that IL17A haplotypes contributed to the development of CAD. In the present study, we found that the rs3748067 gene polymorphism was associated with an elevated risk of CAD, which is different with the results of previous studies. Such a discrepancy may be caused by differences in the ethnicities of the populations under investigation, study designs, sample sizes, or 
simply by chance. Further studies are greatly needed to confirm our findings.

Two limitations should be considered in the present study. First, selection bias could not be avoided due to the hospital-based design, although the gender and age matching between patients and controls may have reduced this bias. Second, the sample size of patients and controls was relatively small, which may have limited the statistical power to find differences between the two groups. Therefore, studies with larger sample sizes are greatly required to confirm our results.

In summary, we found that the rs3748067 gene polymorphism is associated with an increased risk of CAD, especially with regard to smokers. Further genetic studies with large sample sizes are required to confirm the relationship between IL17 gene polymorphisms and risk of CAD.

\section{Conflicts of interest}

The authors declare no conflict of interest.

\section{REFERENCES}

Bulat-Kardum LJ, Etokebe GE, Lederer P, Balen S, et al. (2015). Genetic Polymorphisms in the Toll-like Receptor 10, Interleukin (IL)17A and IL17F Genes Differently Affect the Risk for Tuberculosis in Croatian Population. Scand. J. Immunol. 82: 6369. http://dx.doi.org/10.1111/sji.12300

Erbel C, Akhavanpoor M, Okuyucu D, Wangler S, et al. (2014). IL-17A influences essential functions of the monocyte/ macrophage lineage and is involved in advanced murine and human atherosclerosis. J. Immunol. 193: 4344-4355. http://dx.doi.org/10.4049/jimmunol.1400181

Greenland P, Alpert JS, Beller GA, Benjamin EJ, et al.; American College of Cardiology Foundation; American Heart Association (2010). $2010 \mathrm{ACCF} / \mathrm{AHA}$ guideline for assessment of cardiovascular risk in asymptomatic adults: a report of the American College of Cardiology Foundation/American Heart Association Task Force on Practice Guidelines. J. Am. Coll. Cardiol. 56: e50-e103. http://dx.doi.org/10.1016/j.jacc.2010.09.001

Isailovic N, Daigo K, Mantovani A and Selmi C (2015). Interleukin-17 and innate immunity in infections and chronic inflammation. J. Autoimmun. 60: 1-11.http://dx.doi.org/10.1016/j.jaut.2015.04.006

Li J, Tian H, Jiang HJ and Han B (2014). Interleukin-17 SNPs and serum levels increase ulcerative colitis risk: a meta-analysis. World J. Gastroenterol. 20: 15899-15909.http://dx.doi.org/10.3748/wig.v20.i42.15899

Lifanov AD, Khadyeva MN, Demenev SV, Knyazev AN, et al. (2014). Association of G197 polymorphism of IL-17A gene with myocardial remodeling and aerobic performance in athletes. Bull. Exp. Biol. Med. 157: 659-662. http://dx.doi.org/10.1007/s10517-014-2638-2

Mormile R (2015). Multiple sclerosis and susceptibility to cardiovascular diseases: Implications of ethnicity-related interleukin17A gene polymorphism? Med. Hypotheses 85: 365-366.http://dx.doi.org/10.1016/j.mehy.2015.06.006

Narbutt J, Wojtczak M, Zalińska A, Salinski A, et al. (2015). The A/A genotype of an interleukin-17A polymorphism predisposes to increased severity of atopic dermatitis and coexistence with asthma. Clin. Exp. Dermatol. 40: 11-16. http://dx.doi.org/10.1111/ced.12438

Pei F, Han Y, Zhang X, Yan C, et al. (2009). Association analysis of the IL-17F His161Arg polymorphism in myocardial infarction. Coron. Artery Dis. 20: 513-517.http://dx.doi.org/10.1097/MCA.0b013e328332a6c3

Vargas-Alarcón G, Angeles-Martínez J, Villarreal-Molina T, Alvarez-León E, et al. (2015). Interleukin-17A gene haplotypes are associated with risk of premature coronary artery disease in Mexican patients from the Genetics of Atherosclerotic Disease (GEA) study. PLoS One 10: e0114943.http://dx.doi.org/10.1371/journal.pone. 0114943

Wang H, Zhang Y, Liu Z, Zhang Y, et al. (2015). The IL-17A G-197A and IL-17F 7488T/C polymorphisms are associated with increased risk of cancer in Asians: a meta-analysis. Drug Des. Devel. Ther. 9: 5159-5168.

Weber C and Hristov M (2015). Atherogenesis and inflammation. From cellular mediators to regulatory mechanisms of inflammation in atherosclerosis. Hamostaseologie 35: 99-101, 101.

Zeng L, Wang Y, Liu J, Wang L, et al. (2013). Pro-inflammatory cytokine network in peripheral inflammation response to cerebral ischemia. Neurosci. Lett. 548: 4-9.http://dx.doi.org/10.1016/j.neulet.2013.04.037

Zhang X, Pei F, Zhang M, Yan C, et al. (2011). Interleukin-17A gene variants and risk of coronary artery disease: a large angiography-based study. Clin. Chim. Acta 412: 327-331.http://dx.doi.org/10.1016/j.cca.2010.10.027 